\title{
Antarctic Water Tracks: Microbial Community Responses to Variation in Soil Moisture, pH, and Salinity
}

\author{
Scott F. George ${ }^{1 *}$, Noah Fierer ${ }^{2}$, Joseph S. Levy ${ }^{3}$ and Byron Adams ${ }^{1,4}$ \\ ${ }^{1}$ Department of Biology, Brigham Young University, Provo, UT, United States, ${ }^{2}$ Department of Ecology and Evolutionary \\ Biology and Cooperative Institute for Research in Environmental Sciences, University of Colorado Boulder, Boulder, CO, \\ United States, ${ }^{3}$ Department of Geology, Colgate University, Hamilton, NY, United States, ${ }^{4}$ Monte L. Bean Museum, Brigham \\ Young University, Provo, UT, United States
}

OPEN ACCESS

Edited by: Laura Zucconi, University of Tuscia, Italy

Reviewed by:

Fabiana Canini,

University of Tuscia, Italy

David A. Lipson,

San Diego State University,

United States

*Correspondence:

Scott F. George

scott.f.george@byu.edu

Specialty section:

This article was submitted to

Extreme Microbiology,

a section of the journal

Frontiers in Microbiology

Received: 13 October 2020

Accepted: 04 January 2021

Published: 27 January 2021

Citation:

George SF, Fierer N, Levy JS and Adams B (2021) Antarctic Water

Tracks: Microbial Community

Responses to Variation in Soil

Moisture, $\mathrm{pH}$, and Salinity.

Front. Microbiol. 12:616730.

doi: 10.3389/fmicb.2021.616730
Ice-free soils in the McMurdo Dry Valleys select for taxa able to cope with challenging environmental conditions, including extreme chemical water activity gradients, freezethaw cycling, desiccation, and solar radiation regimes. The low biotic complexity of Dry Valley soils makes them well suited to investigate environmental and spatial influences on bacterial community structure. Water tracks are annually wetted habitats in the cold-arid soils of Antarctica that form briefly each summer with moisture sourced from snow melt, ground ice thaw, and atmospheric deposition via deliquescence and vapor flow into brines. Compared to neighboring arid soils, water tracks are highly saline and relatively moist habitats. They represent a considerable area $\left(\sim 5-10 \mathrm{~km}^{2}\right)$ of the Dry Valley terrestrial ecosystem, an area that is expected to increase with ongoing climate change. The goal of this study was to determine how variation in the environmental conditions of water tracks influences the composition and diversity of microbial communities. We found significant differences in microbial community composition between on- and offwater track samples, and across two distinct locations. Of the tested environmental variables, soil salinity was the best predictor of community composition, with members of the Bacteroidetes phylum being relatively more abundant at higher salinities and the Actinobacteria phylum showing the opposite pattern. There was also a significant, inverse relationship between salinity and bacterial diversity. Our results suggest water track formation significantly alters dry soil microbial communities, likely influencing subsequent ecosystem functioning. We highlight how Dry Valley water tracks could be a useful model system for understanding the potential habitability of transiently wetted environments found on the surface of Mars.

Keywords: Antarctica, Mars analog, water tracks, microbial ecology, extremophiles

\section{INTRODUCTION}

The abiotic extremes characteristic of the McMurdo Dry Valleys (MDV) region (77-78 ${ }^{\circ}$ S, $160-$ $164^{\circ} \mathrm{E}$ ) (Fountain et al., 1999) select for particular taxa able to cope with the unique environmental conditions (Cary et al., 2010; Doran et al., 2010). The MDV region is a polar desert ecosystem with average air temperatures of $-18^{\circ} \mathrm{C}$, winter lows of $-65^{\circ} \mathrm{C}$, and summer temperatures that fluctuate 
around $0^{\circ} \mathrm{C}$ (Doran et al., 2002). Annual precipitation is limited to 3-50 mm (water equivalent) of snow (Fountain et al., 2010), most of which sublimates before entering a liquid phase (Chinn, 1993), making a vast majority of the terrestrial habitat highly arid. Fast, dry drainage winds descend from the polar plateau with speeds up to $37 \mathrm{~m} \mathrm{~s}^{-1}$, warming valley floors and lowering relative humidity, resulting in further desiccation of surface soils (Nylen et al., 2004). Soil salinity is extremely variable in coastal MDV, with solute salt concentrations ranging from 0 to 6000 eq $\mathrm{m}^{-2}$ from young coastal lowland surfaces to ancient glacial tills further inland (Toner et al., 2013). Biota within this region are also subject to dynamic solar radiation regimes, including 4 months of near or constant darkness (Dana et al., 1998).

The MDV lack vertebrates and vascular plants, with photosynthetic primary productivity limited to patchy distributions of cyanobacteria and algae found in lakes (Vincent et al., 1993), seasonally wetted streams and soils (Hawes and Howard-Williams, 2013; Stanish et al., 2013; Niederberger et al., 2015), and lithic niches (Friedmann and Ocampo, 1976; Friedmann, 1982; Pointing et al., 2009). The low complexity of this desert ecosystem makes it a well-suited natural system to investigate physical and chemical controls on soil microbial communities, with generalized findings that can be applied to other habitats (Van Horn et al., 2013).

Liquid water availability limits biological activity within this habitat where water availability is primarily regulated by low temperatures and limited net snow accumulation. During austral spring and summer, a hydrological continuum forms in MDV soils as differentially warmed soils and spatially heterogeneous snow and ice reservoirs generate different volumes of transient liquid water (Levy, 2015). These wetted soil areas in the cold desert range from those that are spatially extensive and perennial, such as glacier-fed streams and lakes, to those that are meterscale and episodic and include hyporheic zones (i.e., wetted soils around and under lakes, ponds, and streams) (McKnight et al., 2007; Niederberger et al., 2015; Lee et al., 2018), water tracks (channelized subsurface groundwater flow) (Levy et al., 2011, 2013; Gooseff et al., 2013), and "wet patches" that form via deliquescence when exposed hygroscopic salts in the soil absorb atmospheric water vapor and generate liquid solutions (Seinfeld and Pandis, 2006; Levy et al., 2012).

Remote sensing data suggest that transiently wetted soils, specifically those removed from surface water bodies, occupy $\sim 5-10 \mathrm{~km}^{2}$ of the landscape during the seasonal thaw (Langford et al., 2015), a small but significant area that is projected to increase within this region due to ongoing climate change (Fountain et al., 2014). Previous work on water track physical, chemical, and biological processes suggest that water track soils are wetter, saltier, finer-grained, and more organicmatter-rich than adjacent, off-track soils (Levy et al., 2013; Ball and Levy, 2015).

At the surface, Antarctic water tracks are identified as visibly damp (dark) soils which grow downslope each summer with the release of meltwater from snow, glaciers, and ground ice (Harris et al., 2007; Levy et al., 2011). Water track liquids flow within the active layer beneath the soil surface but above the ice table, which is located above permanently frozen soil (Levy et al., 2011). Water track soil moisture and soil salinity are generally 5-10 times higher than other arid desert soils in the Dry Valleys (Gooseff et al., 2013; Levy et al., 2013). Accordingly, water tracks represent a pronounced alteration to the desert ecosystem and their presence may result in important shifts in soil microbial community composition, diversity, and ecosystem functioning.

Water tracks have been proposed as useful model systems for the episodically formed features on Mars termed recurring slope lineae (RSL) (Levy, 2012), which, like water tracks, are darktoned, meter-scale features that grow downslope for hundreds of meters during seasonal warm periods (McEwen et al., 2011; Stillman et al., 2017). Among other similar characteristics, water tracks possess hygroscopic salts capable of deliquescence (Levy et al., 2011; Gooseff et al., 2013), which may contribute additional soil moisture beyond that derived from meltwater sources alone. Deliquescence has been identified as a mechanism for plausible transient water formations on Mars (Rennó et al., 2009; Smith et al., 2009; Martín-Torres et al., 2015), including RSL (Ojha et al., 2015). However, the role, quantity, or even presence of water in RSL has been challenged (Edwards and Piqueux, 2016; Dundas et al., 2017; Schmidt et al., 2017).

McMurdo Dry Valleys water tracks may be more analogous to transiently wetted habitats found historically on Mars. Over the last $\sim 3.5$ billion years, it appears that surface environments on Mars experienced a series of climate successions from cold and semiarid to ultimately a hyperarid state (e.g., Carr and Head, 2010; Mahaffy et al., 2013). These climatic shifts on Mars would have had a significant impact on the evolution of an early Martian biosphere (Davila and Schulze-Makuch, 2016). It is plausible that early in Mars' history ( 3.5 billion years ago), transiently wetted environments similar to Antarctic water tracks existed at the margins of highlands glaciated regions (Wordsworth, 2016), and if so, they would have represented important niches within the increasingly cold and arid planet.

Previous biological investigations of the Dry Valley water tracks are limited in number and have yet to produce concordant conclusions. In some cases, water track soil moisture enhancement has shown to elevate levels of microbial biomass relative to neighboring dry soils (Van Horn et al., 2013; ChanYam et al., 2019), though this increase has not always been observed (Ball and Levy, 2015). Other work suggests water tracks promote microbial activity, as measured by phosphorus depletion (Gooseff et al., 2013), $\mathrm{CO}_{2}$ fluxes (Ball and Levy, 2015), and in vitro microcosm radio-respiration assays (Chan-Yam et al., 2019). However, water track fluids are also highly saline, creating "dead zones" in the polar desert that limit habitability to only the most halotolerant organisms (Ball and Levy, 2015). Isolated "wet patches" can be so saline as to exceed water activity limits for cellular growth and reproduction (Levy et al., 2012; Rummel et al., 2014). An investigation of nematodes, the most abundant metazoan in the Dry Valleys, showed pronounced declines in population numbers when measured within water track soils (Gooseff et al., 2013). Several studies have found microbial communities in transiently wetted soils and water tracks have significantly different compositions compared to neighboring arid soils (Van Horn et al., 2014; Niederberger et al., 2015; 
Lee et al., 2018), although these differences has not always been observed (Chan-Yam et al., 2019).

One possible confounding factor that may have affected previous studies is differences in soil age and accumulated soil salinity. In an effort to mitigate this effect, we examined sediment profiles from two proximal locations with similar microclimate conditions, but different soil ages. The Goldman Glacier Basin (GB) water track flows through older, Taylor IV tills (2.1-37 Ma), while Water Track 1 (WT1) in the Lake Hoare basin flows through younger mixed Taylor III/Bonney tills (74-210 ka) (Bockheim et al., 2008).

We set out to identify how variation in the measured physical and chemical environment of water tracks within these two water track systems influence soil microbial community structure and diversity. A total of twenty samples from on- and off-track soils were analyzed to assess abiotic influences on microbial composition and diversity. Soil bacterial biodiversity was assessed using cultivation independent $16 \mathrm{~S}$ rRNA gene sequencing.

We hypothesized that soil salinity, moisture, and $\mathrm{pH}$ are significantly different within water tracks than outside of them, and that these geochemical factors are significantly correlated with microbial community structure and diversity. We also hypothesized that soil microbial community composition is significantly different between on-track and off-track habitats, and between the two tested water track systems in Taylor Valley. Namely, the Goldman Glacier Basin water track, and that of the Lake Hoare Basin, Water Track 1. We further hypothesized that the seasonal formation of water tracks results in significantly higher community diversity, richness, and evenness compared to off-track habitats due to increased water availability. Finally, we hypothesized that soil position (i.e., on-track and off-track), salinity, moisture, $\mathrm{pH}$, and the two different site locations of water track systems are significant explanatory variables for soil microbial community composition.

\section{MATERIALS AND METHODS}

\section{Sampling and Soil Geochemistry}

Soil samples and pore water were collected from the Lake Hoare and Goldman Glacier Basins of Taylor Valley, Antarctica during the austral summer of 2012-2013. Two separate water track systems within Taylor Valley were selected for analysis, Water Track $1\left(77.64^{\circ} \mathrm{S}, 162.94^{\circ} \mathrm{E}\right)$ and Goldman Glacier Basin $\left(77.67^{\circ} \mathrm{S}\right.$, $162.93^{\circ} \mathrm{E}$ ), which are approximately $3.3 \mathrm{~km}$ apart. Sediment and pore water collected from the darkened portions of water tracks are designated here as "on-track," and samples from the adjacent lighter soils are classified as "off-track." Off-track samples were located at least $5 \mathrm{~m}$ from the current edge of the water track (Levy et al., 2013). Wet, on-track soils have a typical albedo of 0.15 , while the off-track soil albedo is generally 0.22 (Levy et al., 2013), making them readily distinguishable in the field. Samples were collected from the upper $10 \mathrm{~cm}$ of the soil horizon using aseptic techniques and were stored in sterile Whirl-Pak bags at $-20^{\circ} \mathrm{C}$ until processing. Latitude and longitude of the collected samples, as well as sample states (i.e., on-track or off-track), were recorded at the time of collection (see Table 1 for details).
TABLE 1 | Summary of sample abiotic properties.

\begin{tabular}{|c|c|c|c|c|c|c|c|}
\hline Sample & $\begin{array}{c}\text { On-/off- } \\
\text { water } \\
\text { track }\end{array}$ & System & $\begin{array}{c}E C \\
(\mathrm{dS} / \mathrm{m})\end{array}$ & GWC (\%) & $\mathrm{pH}$ & Latitude & Longitude \\
\hline 1 & Off & WT1 & 0.02 & 2.03 & 7.99 & -77.6393 & 162.9406 \\
\hline 2 & Off & WT1 & 0.03 & 2.07 & 8.43 & -77.6428 & 162.9303 \\
\hline 3 & Off & $\mathrm{GB}$ & 0.00 & 2.48 & 8.49 & -77.6669 & 162.9250 \\
\hline 4 & On & GB & 0.19 & 3.47 & 8.30 & -77.6668 & 162.9258 \\
\hline 5 & Off & WT1 & 0.01 & 1.31 & 8.33 & -77.6326 & 162.9340 \\
\hline 6 & On & WT1 & 0.08 & 7.57 & 8.24 & -77.6427 & 162.9300 \\
\hline 7 & On & WT1 & 0.05 & 3.79 & 8.34 & -77.6458 & 162.9177 \\
\hline 8 & Off & GB & 0.05 & 1.00 & 8.40 & -77.6690 & 162.9262 \\
\hline 9 & On & WT1 & 0.16 & 1.51 & 8.31 & -77.6364 & 162.9354 \\
\hline 10 & On & WT1 & 0.07 & 0.79 & 8.41 & -77.6392 & 162.9404 \\
\hline 11 & On & GB & 0.47 & 4.35 & 8.35 & -77.6720 & 162.9325 \\
\hline 12 & Off & WT1 & 0.01 & 2.63 & 8.84 & -77.6460 & 162.9182 \\
\hline 13 & On & WT1 & 0.05 & 2.84 & 8.06 & -77.6345 & 162.9351 \\
\hline 14 & Off & WT1 & 0.01 & 1.66 & 8.02 & -77.6363 & 162.9359 \\
\hline 15 & On & GB & 0.05 & 4.98 & 7.96 & -77.6690 & 162.9256 \\
\hline 16 & On & GB & 0.73 & 2.18 & 8.00 & -77.6644 & 162.9253 \\
\hline 17 & On & WT1 & 0.25 & 3.81 & 8.13 & -77.6364 & 162.9353 \\
\hline 18 & Off & WT1 & 0.01 & 1.31 & 8.37 & -77.6326 & 162.9340 \\
\hline 19 & Off & GB & 0.01 & 2.02 & - & -77.6721 & 162.9322 \\
\hline 20 & Off & GB & 0.09 & 2.34 & 7.99 & -77.6644 & 162.9266 \\
\hline
\end{tabular}

Gravimetric water content (GWC) was calculated to obtain soil moisture values for each sample. Electrical conductivity (EC), a proxy of salinity, was also measured for each sample. GWC was calculated as the percentage of dry weight of sediment per sample, drying approximately $100 \mathrm{~g}$ of soil at $105^{\circ} \mathrm{C}$ for 24 hours and then reweighing the sample. EC $(\mathrm{dS} / \mathrm{m})$ was obtained for each sample using a Decagon Devices 5TE probe. Soil pH was measured in a 1:2 0.01 $\mathrm{M} \mathrm{CaCl}_{2}$ solution (Thermo Orion $\mathrm{pH}$ Meter Model 410A+, Thermo Electron, Waltham, MA, United States).

\section{DNA Extraction and Taxonomic Profiling}

DNA extraction and microbial community analyses were conducted using the cultivation-independent 16S rRNA gene sequencing approach as described in Prober et al. (2015). Total genomic DNA was extracted from each soil sample using the MO BIO's PowerSoil DNA Isolation Kit (MO BIO Laboratories Inc., Carlsbad, CA, United States). For microbial analyses, the V4 hypervariable region of the $16 \mathrm{~S}$ rRNA gene was PCR amplified using the 515f and 806r primer pair which captures both Bacteria and Archaea. Three PCRs were run per sample, with the amplicons from the replicate reactions pooled. Each primer pair included Illumina adapters and 12-bp error-correcting barcodes unique to each sample (Thompson et al., 2017). After gel visualization to confirm amplification, we used a PicoGreen dsDNA assay to quantify amplicon yields, with the amplicons then pooled together in equimolar concentrations for sequencing on the Illumina MiSeq instrument. DNA sequencing was completed at the University of Colorado Next Generation Sequencing Facility using the $2 \times 150$ bp paired-end 
sequencing chemistry. Four DNA extraction and four notemplate PCR "blanks" were included in the run to check for potential contamination.

Sequences were demultiplexed using a custom Python script ('prep_fastq_for_uparse.py'1), with the UPARSE pipeline used for quality filtering and phylotype (i.e., operational taxonomic unit) clustering (Edgar, 2013). Quality filtering was conducted using a maximum e-value of 0.5 with paired-end sequences merged prior to downstream processing. Representative sequences from returned phylotypes that were not $\geq 75 \%$ similar to sequences contained in the Greengenes database (McDonald et al., 2012) were removed; afterward, the raw sequences were mapped to phylotypes at a $97 \%$ similarity cutoff. Taxonomic classification of each phylotype was determined using the Ribosomal Database Project classifier (Wang et al., 2007) against the Greengenes database with a confidence threshold of 0.5 .

\section{Statistical Analyses}

To determine soil chemical and physical effects on community structure, statistical tests of inter- and intra-site relationships and differences were undertaken. Accordingly, phylotype data were rarefied in $\mathrm{R}$ ( $\mathrm{R}$ Core Team, 2017) to 11,649 reads per sample with the vegan package (Oksanen et al., 2019) before all diversity analyses. Alpha diversity metrics were calculated using the microbiome package (Lahti and Shetty, 2012), for Pielou's evenness, and the vegan package (Oksanen et al., 2019), for Shannon diversity $\left(\mathrm{H}^{\prime}\right)$ (Supplementary Table S1). Independent $t$-tests of the alpha diversity metrics between on and off-track samples were run in SPSS (IBM, 2016). Phyla relative abundances (Figure 1 and Supplementary Table S2) were calculated with the funrar package (Grenié et al., 2017). Stacked histograms and clustered box plots for phyla relative abundances were generated with SPSS (IBM, 2016).

To test for correlations between community composition and measured soil properties, Mantel tests based on Pearson's product-moment correlations were run for each variable using the vegan package (Oksanen et al., 2019). Hypotheses regarding relationships between soil properties and microbial diversity, richness, and evenness were also explored using Pearson correlation tests. Mann-Whitney $\mathrm{U}$ and independent $t$-tests, as appropriate, were used to test significant differences in soil chemical and physical properties between on- and offtrack samples.

PERMANOVA tests, with pairwise distances calculated using Bray-Curtis distance, were run in the vegan package (Oksanen et al., 2019) to test for significant differences in soil microbial communities between on-track and off-track samples; WTI and GB systems; on-track communities of GB and on-track communities of WT1; and finally, off-track communities of GB and off-track communities of WT1. A multidimensional scaling (MDS) plot informed by a Bray-Curtis dissimilarity matrix was created in the vegan package (Oksanen et al., 2019) to represent microbial community clustering based on sample type (On/Offtrack) and water track system (GB/WT1) within the axes of soil salinity, moisture, and $\mathrm{pH}$.

\footnotetext{
${ }^{1}$ https://github.com/leffj/helper-code-for-uparse
}

Redundancy analysis (RDA) with variation partitioning was run using the vegan package (Oksanen et al., 2019) to estimate the percent at which the measured abiotic variables, individually and collectively, explained microbial community composition in the tested soils. ANOVA tests were run on the specific canonical axes produced from the underlying RDAs to see if the explanatory variables were significant in the partition variance.

\section{RESULTS}

\section{Soil Properties}

The mean on-track soil moisture of the Lake Hoare Basin water tracks was significantly higher than the adjacent off-track soils $(P=0.03)$. Water track soil moisture was, on average, $\sim 1.9$ times higher than neighboring dry soil (3.53-1.89\%), ranging from $0.79-7.57 \%$ on-track, and 1.00-2.63\% off-track (Table 1).

On-track soil values were also significantly more saline ( $U=93.5, P<0.001)$ than the proximal off-track counterparts. Median salinity on-track was ten times higher than off-track $(0.12 \mathrm{dS} / \mathrm{m}$ compared to $0.01 \mathrm{dS} / \mathrm{m})$. The range of on-track salinities were more variable $(0.05 \mathrm{dS} / \mathrm{m}$ to $0.73 \mathrm{dS} / \mathrm{m})$ than offtrack salinities, which were consistently low across the tested samples $(0.00 \mathrm{dS} / \mathrm{m}$ to $0.09 \mathrm{dS} / \mathrm{m})$.

Soil $\mathrm{pH}$ was fairly uniform across all samples, with no significant difference in the mean $\mathrm{pH}$ between on-track and offtrack soils ( 8.21 and 8.32 , respectively) $(P=0.31)$ (Table 1). There was no apparent correlation between any of the measured abiotic variables, namely: moisture and $\mathrm{pH}[r(19)=-0.16, P=0.52], \mathrm{pH}$ and salinity $[r(19)=-0.25, P=0.30]$, and salinity and moisture $[r(20)=0.52, P=0.15]$.

\section{Microbial Communities}

Across all samples, we detected a total of 1457 unique phylotypes after rarefaction, with the number of phylotypes per sample ranging from 182 to 713 (Supplementary Table S1). Eight archaeal phylotypes, not included in analyses here, were identified as belonging to two phyla, and represented $<0.23 \%$ of the sequences. On-track samples had higher average numbers of phylotypes (420 phylotypes per sample \pm 56 ) compared to offtrack samples (392 \pm 32 ), though this was not significant $(P>0.7)$. There was also no significant difference in average Shannon diversity $(P>0.4)$ between on-track $(4.13 \pm 0.23)$ and off-track $(4.37 \pm 0.12)$ samples. Pielou's evenness was not significantly different on- or off-track $(P>0.1)$, although it was higher off-track than on-track $(0.74 \pm 0.01,0.69 \pm 0.03)$.

The majority of recovered microbial communities were comprised of a handful of phyla (Figure 1 and Supplementary Table S2), particularly Actinobacteria, which was the most abundant phylum detected in soils both on and off water tracks (27.6\% and $48 \%$ of reads, respectively). Other abundant phyla on and off water tracks included Proteobacteria $(23.8 \%, 10.6 \%)$, Bacteroidetes (17.4\%, 4.8\%) Gemmatimonadetes (10.4\%, 4.4\%) and Acidobacteria $(8.5 \%, 16.8 \%)$. The relative abundance of these five phyla, from the 25 phyla identified, accounted for $87.7 \%$ of all communities on-track and $84.5 \%$ of those off-track (Supplementary Table S2). For some phyla, the intra-sample 


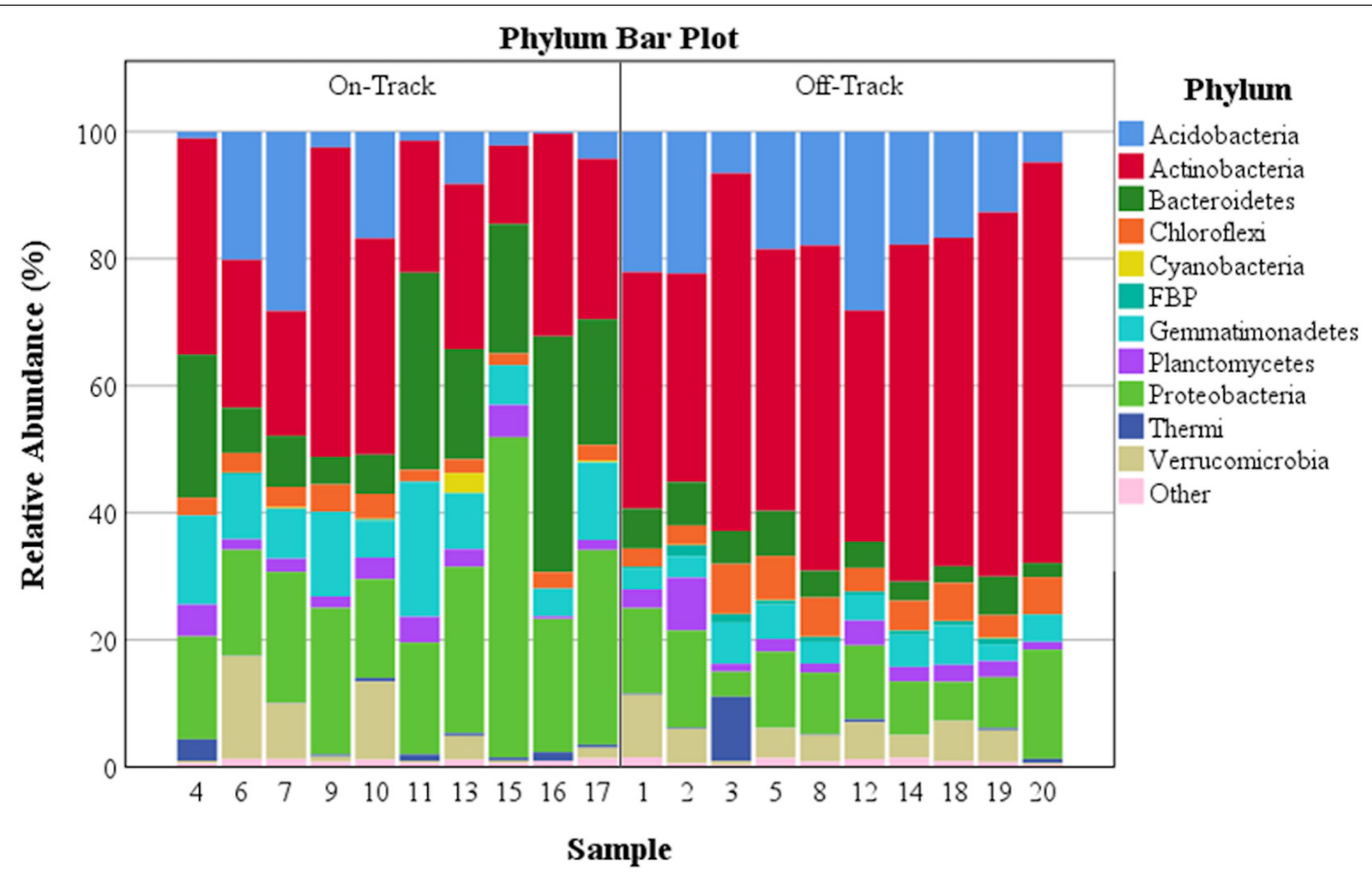

FIGURE 1 | The percent relative abundance of major soil bacterial taxa across all samples. Phyla with a relative abundance $>0.39 \%$ either on or off water tracks are identified.

(e.g., on-track versus on-track) variation in relative abundances was considerable (Figure 2).

We observed a high degree of variation in the composition of bacterial communities, with community composition patterns correlated with select physiochemical properties and spatial scale (Figure 3). On-track microbial communities were significantly different than those off-track (PERMANOVA $R^{2}=0.203$, $P<0.001)$. Microbial communities between the GB and WTI water track systems were also significantly different (PERMANOVA $R^{2}=0.156, P=0.004$ ). Finally, comparisons of intra-track types between systems, namely on-track to on-track and off-track to off-track soils between GB and WT1, showed significant differences in microbial communities (PERMANOVA $R^{2}=0.33, P=0.01$, PERMANOVA $R^{2}=0.208$, $P=0.03$, respectively). On-track communities in the MDS plot were distinctly clustered with each other, as were off-track communities and assemblages based on system (GB/WT1) (Figure 3).

A Mantel statistic based on Pearson's correlation showed a statistically significant relationship between soil salinity and community composition $[r(20)=0.41, P=0.005]$. However, a Mantel test exploring possible correlations between soil moisture and microbial community composition was not significant $[r(20)=0.20, P=0.065]$, as was the relationship between $\mathrm{pH}$ and community composition $[r(19)=-0.04, P=0.58]$. Salinity was the only environmental variable that was significantly correlated with microbial diversity $\left(\mathrm{H}^{\prime}\right)[r(20)=-0.537, P=0.02]$, richness $[r(20)=-0.45, P=0.045]$, and evenness $\left(H^{\prime}\right)[r(20)=-0.48$,
$P=0.03]$. In all instances, as salinity increased these diversity metrics declined.

Redundancy analysis with variance partitioning showed highly similar patterns with the Mantel tests. Specifically, RDA with variance partitioning estimated that collectively, sample location in regard to water tracks (On/Off-Track), soil salinity, and the water track system location (WT1/GB) were significant explanatory variables for $22.7 \%$ of the tested soils' microbial community composition (ANOVA, $P=0.002$ ). Sample location (On/Off-Track) explained $5.8 \%$ of the variation in community composition conditioned on the other variables included in the model (ANOVA, $P=0.03$ ). For soil salinity, this was $7.7 \%$ (ANOVA, $P=0.046$ ), and for system location, it was $6.7 \%$ (ANOVA, $P=0.02$ ). The canonical axes of soil moisture and $\mathrm{pH}$ were not significant explanatory variables in structuring the tested microbial communities (ANOVA, $P=0.38, P=0.58$, respectively).

\section{DISCUSSION}

The annual formation of water tracks in this polar desert ecosystem represents a significant alteration in this relatively lowcomplexity terrestrial landscape. Similar to other observations (Gooseff et al., 2013; Levy et al., 2013), our tested average water track salinity was an order of magnitude and significantly higher than adjacent 'non-water track' soils. The observed differences in community composition were most strongly associated with 


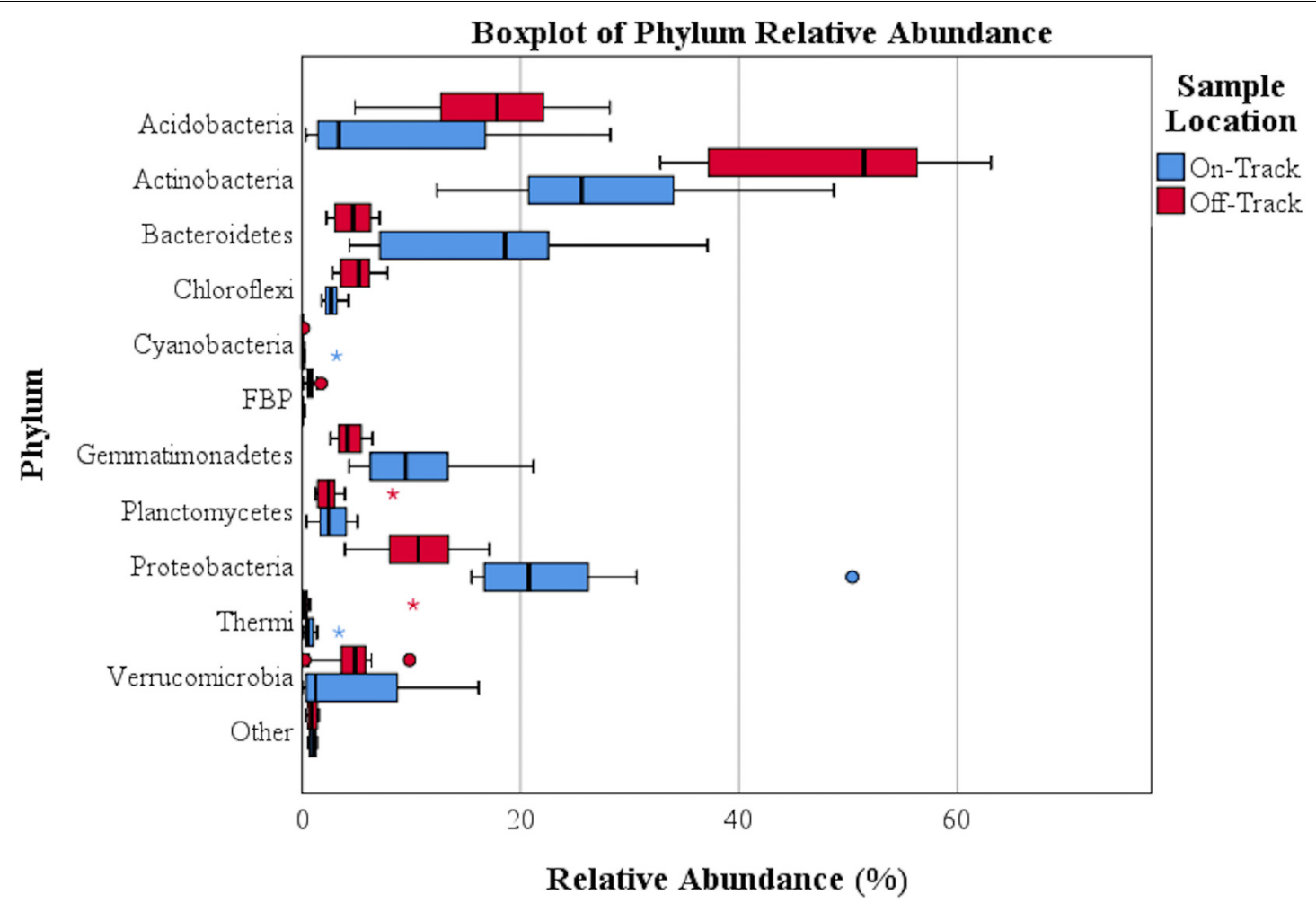

FIGURE 2 | A boxplot of bacterial relative abundance on and off the tested water tracks. Asterisks represent extreme outliers; solid circles represent standard outliers. Phyla with a relative abundance $>0.39 \%$ either on or off water tracks are identified.

differences in soil salinity (Figure 3), a pattern that is in agreement with previous studies (Lee et al., 2012; Van Horn et al., 2013). As salinity increased, the relative abundance of Bacteroidetes increased considerably, with observed decreases in Actinobacteria, suggesting a shift toward a more halotolerant community. No correlations were found among soil salinity, $\mathrm{pH}$, and moisture.

We observed no significant differences in average diversity, richness, or evenness between on-track and off-track soils, in spite of nearly twofold increases in soil moisture and tenfold increases in salinity when on track. However, soil salinity was significantly correlated with diversity, richness and evenness, and in all cases the relationship was negative. Similar significant soil salinity relationships with microbial diversity (Zeglin et al., 2011; Van Horn et al., 2014) have been observed elsewhere in the Dry Valleys. Salinity measured by Zeglin et al. (2011) was largely within the range measured in our study. Salinity measured by Van Horn et al. (2014) reached levels several orders of magnitude above ours, yet the same relationship was exhibited. Our findings suggest that MDV soil microbial richness is sensitive to even moderate changes in salinity, with higher soil salinities associated with less diverse bacterial communities.

Soil salinity can have a pronounced direct and indirect affect in shaping microbial communities and their ecological responses (Rietz and Haynes, 2003; Lozupone and Knight, 2007; Rath and Rousk, 2015; O'Brien et al., 2019; Rath et al., 2019). Salt-affected soils generally show decreases in microbial respiration (Sardinha et al., 2003; Yuan et al., 2007), biomass (Rietz and Haynes, 2003; Yuan et al., 2007), and extracellular enzymatic activity (Rietz and Haynes, 2003; Ghollarata and Raiesi, 2007). In more extreme cases, as demonstrated in aquatic habitats, elevated salt concentrations can prevent metabolic activity (Oren, 2013) and inhibit life via denaturing of biological macromolecules (Hallsworth et al., 2007). However, microbial communities within salt-affected areas should exhibit adaptive and taxonomic responses if the salinity is elevated to meaningful ecological levels (Rath and Rousk, 2015; GundeCimerman et al., 2018; O’Brien et al., 2019), which may alter at least some ecosystem functions (Kimbrel et al., 2018; Rath et al., 2019).

The absence we observed of statistically significant correlations between water content and community composition in the MDV was also observed in several, though not all, sites sampled by Van Horn et al., 2013. Chan-Yam et al. (2019) similarly found no significant correlation between community composition and soil moisture content from their MDV soil investigations. However, our MDS plot strongly hints that water content, which can be seasonally dynamic, may play an important role in community structure.

Soil $\mathrm{pH}$ has been shown to have a strong influence on bacterial community structure at the continental scale (Fierer and Jackson, 2006; Lauber et al., 2009). Regional analyses looking at the influence of soil $\mathrm{pH}$ on microbial communities in Antarctica are in agreement with these large-scale studies (Smith et al., 2010; 


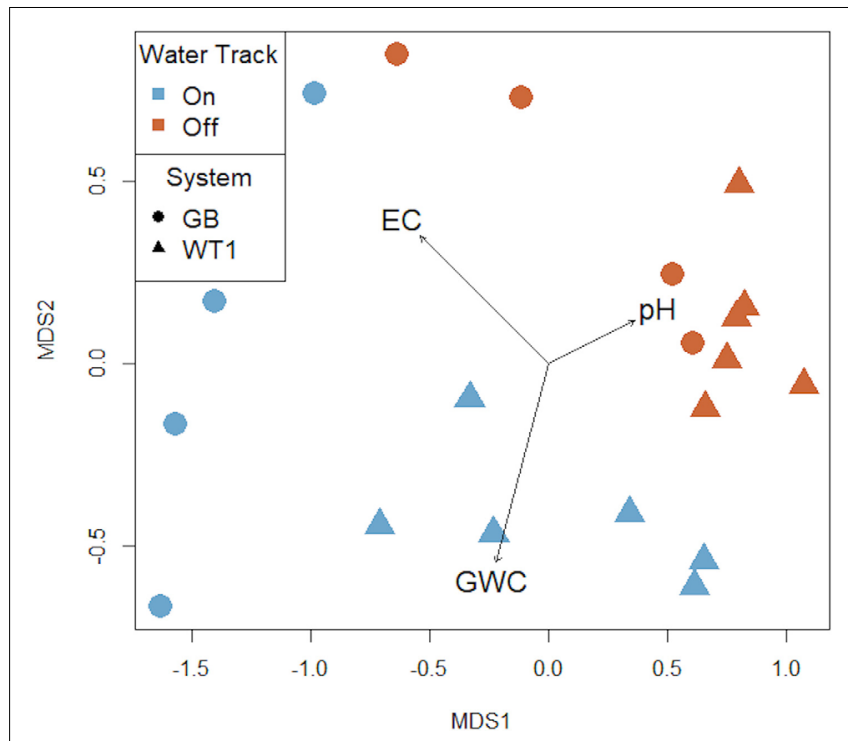

FIGURE 3 | Multidimensional scaling (MDS) plot of soil microbial community composition. Water tracks (blue) harbor significantly different bacterial communities from those collected off-track (red) (PERMANOVA $R^{2}=0.203$, $P=0.001)$. Other significant differences include water track system, namely the Goldman Glacier Basin (GB) and Water Track 1 (WT1) (PERMANOVA $\left.R^{2}=0.156, P=0.004\right)$; on- versus on-track soil communities between $\mathrm{GB}$ and WT1 (PERMANOVA $R^{2}=0.33, P=0.01$ ); and off- versus off-track soils communities between GB and WT1 (PERMANOVA $R^{2}=0.208, P=0.033$ ). The black vectors represent measured environmental parameters $(\mathrm{pH}$, $\mathrm{EC}=$ electrical conductivity, GWC = gravimetric water content) that fit into the ordination space. $R^{2}=0.995$. Stress score $=0.068$ in two dimensions.

Van Horn et al., 2013), as are some localized studies (Van Horn et al., 2013; Chan-Yam et al., 2019). However, other localized Dry Valley investigations failed to find soil $\mathrm{pH}$ as a significant factor in community partitioning (Lee et al., 2018), or being correlated with diversity metrics (Zeglin et al., 2011). Soil pH from our study was reasonably constrained across all collected samples (Table 1), which may be one reason we did not identify significant relationships between it and microbial community composition, diversity, richness or evenness.

The off-track samples had communities dominated by the phyla Acidobacteria, Actinobacteria, Proteobacteria, and to a lesser extent Bacteroidetes, Chloroflexi, Gemmatimonadetes, Verrucomicrobia, and Planctomycetes (Figure $\mathbf{1}$ and Supplementary Table S2). The dominance of these particular phyla within arid MDV soil communities are concordant with previous studies, especially for the phyla Acidobacteria and Actinobacteria (Pointing et al., 2009; Zeglin et al., 2011; Lee et al., 2012; Niederberger et al., 2015). The phyla Acidobacteria and Actinobacteria have also been found to be among the most abundant taxa in the extremely arid and significantly warmer soils of the Atacama Desert in Chile (Crits-Christoph et al., 2013).

On-track soil samples were composed largely of the phyla Acidobacteria, Actinobacteria, Bacteroidetes, Gemmatimonadetes, and Proteobacteria. Acidobacteria and Actinobacteria were the two most dominant phyla off-track, but their abundances dropped nearly in half within water track samples (Figure $\mathbf{1}$ and Supplementary Table S2). Bacteroidetes, Gemmatimonadetes, and Proteobacteria saw dramatic increases in their relative abundances within water track soils.

Other investigations regarding phyla in transiently wetted Dry Valley soils observed similar trends, with the phyla Proteobacteria (Stanish et al., 2013; Niederberger et al., 2015) and Bacteroidetes (Zeglin et al., 2011) as the dominant members in wetter soils.

Several genera were found to be closely related to known extremophilic and extremotolerant taxa. Members from the genus Gillisia (phylum Bacteroidetes) were notably abundant in on-track samples. Closely related psychrophilic isolates from this genus were also found in Antarctic Lake Fryxell of Taylor Valley (Van Trappen et al., 2004), within soils from an Antarctic valley further south (Niederberger et al., 2015), and in Antarctic maritime environments (Bowman and Nichols, 2005). Phylotypes from the genus Rubrobacter (phylum Actinobacteria) were present in every sample, a genus which includes isolates which have been shown to exhibit resistance to ionizing radiation (Rainey et al., 2005) (Ferreira et al., 1999).

The genus Modestobacter (phylum Actinobacteria) was also detected, which has been isolated from the hyperarid Atacama Desert soils of Chile (Busarakam et al., 2016) and from the nearby Asgard Range of Antarctica (Mevs et al., 2000). A phylotype from genus Truepera (phylum Thermi) was also characterized. Truepera has been found in the ephemeral Lake Lucero playa of New Mexico, United States (Sirisena et al., 2018), an episodically wetted environment which shifts between a freshwater habitat and a hypersaline dry desert. Isolates from the genus Truepera have also shown to be highly resistant to ionizing radiation (Albuquerque et al., 2005). Pseudoxanthomonas and Sphingomonas (Phylum Proteobacteria) were present, genera which have been cultured from both saline and freshwater lakes in the Transantarctic Mountains and Shackleton Range of Antarctica (Peeters et al., 2011). The identification of phylotypes closely related to known psychrophilic, halotolerant, and ionizing-radiation-resistant isolates suggests, though does not confirm, adaptations found within the sampled microbial communities.

Other possible explanatory variables in shaping MDV soil microbial structure and diversity are the legacy influences associated with long-term water track presence. Within our study at least one water track system, Water Track 1, has persisted in a remarkably similar form and shape since at least 1911. This valuable information was preserved by photographic evidence gathered during Robert Falcon Scott's Terra Nova Expedition, evidence which has been compared with present-day imagery (Levy et al., 2013). Temporal legacies associated with long-term water track presence may therefore be reasonably important in shaping microbial communities of water tracks, though this is challenging to test. A possible approach could include a time series investigation of newly forming water tracks that are now entering historically dry soils (Fountain et al., 2014).

Water tracks within the MDV region represent a small, though important, area of the cold-arid desert that is anticipated 
to expand with ongoing climate change. Our investigation found significant differences between microbial communities on- and off-water track samples and at different water track system locations. Of the tested variables, we found salinity to be the best predictor of microbial community composition, with Bacteroidetes concentrated at higher levels of salinity and Actinobacteria in low-saline soils. The microbial communities appeared to be sensitive to even moderate variations in salinity. Increases in salinity significantly correlated with decreases in microbial diversity, richness and evenness. There were no significant differences for microbial diversity, richness, or evenness on- and off-track. Soil moisture in this study was significantly higher within water track samples, yet it was not meaningfully correlated with community composition or diversity. Our research suggests this low complexity environment has complex abiotic and spatial influences upon microbial communities. Results from this study indicate water track formation significantly alters the arid soil microbial community composition in Antarctica soils, and therefore, possibly ecosystem functions. Water tracks may also serve as useful models for transiently wetted habitats that may have existed, or exist, on Mars surface.

\section{DATA AVAILABILITY STATEMENT}

The authors acknowledge that the data presented in this study must be deposited and made publicly available in an acceptable repository, prior to publication. Frontiers cannot accept a manuscript that does not adhere to our open data policies. The data presented in this study are deposited in the Environmental Data Initiative (EDI) Repository at https://doi.org/10.6073/pasta/ a98c5ce00cc51d5424b07aebcfcf9f74 (George et al., 2020).

\section{REFERENCES}

Albuquerque, L., Simões, C., Nobre, M. F., Pino, N. M., Battista, J. R., Silva, M. T., et al. (2005). Truepera radiovictrix gen. nov., sp. nov., a new radiation resistant species and the proposal of Trueperaceae fam. nov. FEMS Microbiol. Lett. 247, 161-169. doi: 10.1016/j.femsle.2005. 05.002

Ball, B. A., and Levy, J. (2015). The role of water tracks in altering biotic and abiotic soil properties and processes in a polar desert in Antarctica. J. Geophys. Res. 120, 270-279. doi: 10.1002/2014JG002856

Bockheim, J. G., Prentice, M. L., and McLeod, M. (2008). Distribution of glacial deposits, soils, and permafrost in Taylor Valley, Antarctica. Arctic Antarct. Alpine Res. 40, 279-286. doi: 10.1657/1523-1430

Bowman, J. P., and Nichols, D. S. (2005). Novel members of the family Flavobacteriaceae from Antarctic maritime habitats including Subsaximicrobium wynnwilliamsii gen. nov., sp. nov., Subsaximicrobium saxinquilinus sp. nov., Subsaxibacter broadyi gen. nov., sp. nov., Lacinutrix copepodicola gen. Intern. J. Syst. Evol. Microbiol. 55, 1471-1486. doi: 10.1099/ijs.0.63527-63520

Busarakam, K., Bull, A. T., Trujillo, M. E., Riesco, R., Sangal, V., van Wezel, G. P., et al. (2016). Modestobacter caceresii sp. nov., novel Actinobacteria with an insight into their adaptive mechanisms for survival in extreme hyper-arid Atacama Desert soils. Syst. Appl. Microbiol. 39, 243-251. doi: 10.1016/j.syapm. 2016.03.007

Carr, M. H., and Head, J. W. (2010). Geologic history of Mars. Earth Planet. Sci. Lett. 294, 185-203. doi: 10.1016/j.epsl.2009.06.042

\section{AUTHOR CONTRIBUTIONS}

NF and JL conceived and designed the experiment. JL carried out the field work, with sample processing by JL and SG. SG analyzed the data. SG, NF, JL, and BA wrote the manuscript. All authors contributed to the article and approved the submitted version.

\section{FUNDING}

This study was funded by the United States Antarctic Program and the National Science Foundation with the grants NSF1341629, NSF-1847067, and OPP-1637708 for Long Term Ecological Research.

\section{ACKNOWLEDGMENTS}

We thank the considerable logistical support provided by the United States Antarctic Program and the National Science Foundation in the form of grants NSF-1341629, NSF-1847067, and OPP-1637708 for Long Term Ecological Research. We also thank Trevor Williams, Nick Dragone, and Angela Oliverio for their valuable assistance on this project.

\section{SUPPLEMENTARY MATERIAL}

The Supplementary Material for this article can be found online at: https://www.frontiersin.org/articles/10.3389/fmicb. 2021.616730/full\#supplementary-material

Cary, S. C., McDonald, I. R., Barrett, J. E., and Cowan, D. A. (2010). On the rocks: the microbiology of Antarctic dry valley soils. Nat. Rev. Microbiol. 8, 129-138. doi: $10.1038 /$ nrmicro2281

Chan-Yam, K., Goordial, J., Greer, C., Davila, A., McKay, C. P., and Whyte, L. G. (2019). Microbial activity and habitability of an Antarctic dry valley water track. Astrobiology 19, 757-770. doi: 10.1089/ast.2018.1884

Chinn, T. J. (1993). "Physical hydrology of the Dry Valley lakes," in Antarctic Research Series: Physical and Biogeochemical Processes in Antarctic Lakeseds, eds W. J. Green and E. I. Friedmann (Washington, DC: American Geophysical Union), 1-51. doi: 10.1029/ar059p0001

Crits-Christoph, A., Robinson, C. K., Barnum, T., Fricke, W. F., Davila, A. F., Jedynak, B., et al. (2013). Colonization patterns of soil microbial communities in the Atacama Desert. Microbiome 1, 28-28. doi: 10.1186/2049-2618-1-28

Dana, G. L., Wharton, R. A., and Ralph, D. A. (1998). Solar Radiation in the Mcmurdo Dry Valleys, Antarctica. Washington, DC: American Geophysical Union.

Davila, A. F., and Schulze-Makuch, D. (2016). The last possible outposts for life on Mars. Astrobiology 16, 159-168. doi: 10.1089/ast.2015.1380

Doran, P. T., Lyons, W. B., and McKnight, D. M. (2010). Life in Antarctic Deserts and Other Cold Environments. Cambridge: Cambridge University Press.

Doran, P. T., McKay, C. P., Clow, G. D., Dana, G. L., Fountain, A. G., Nylen, T., et al. (2002). Valley floor climate observations from the McMurdo Dry Valleys, Antarctica, 1986-2000. J. Geophys. Res. Atmos. 107, 1-12. doi: 10.1029/ 2001JD002045

Dundas, C. M., McEwen, A. S., Chojnacki, M., Milazzo, M. P., Byrne, S., McElwaine, J. N., et al. (2017). Granular flows at recurring slope lineae on 
Mars indicate a limited role for liquid water. Nat. Geosci. 10, 903-907. doi: 10.1038/s41561-017-0012-15

Edgar, R. C. (2013). UPARSE: highly accurate OTU sequences from microbial amplicon reads. Nat. Methods 10, 996-998. doi: 10.1038/nmeth.2604

Edwards, C. S., and Piqueux, S. (2016). The water content of recurring slope lineae on Mars. Geophys. Res. Lett. 43, 8912-8919. doi: 10.1002/2016GL070179

Ferreira, A. C., Nobre, M. F., Moore, E., Rainey, F. A., Battista, J. R., and Da Costa, M. S. (1999). Characterization and radiation resistance of new isolates of Rubrobacter radiotolerans and Rubrobacter xylanophilus. Extremophiles 3, 235-238. doi: 10.1007/s007920050121

Fierer, N., and Jackson, R. B. (2006). The diversity and biogeography of soil bacterial communities. Proc. Natl. Acad. Sci. U.S.A. 103, 626-631. doi: 10.1073/ pnas. 0507535103

Fountain, A. G., Levy, J. S., Gooseff, M. N., and Van Horn, D. (2014). The McMurdo Dry Valleys: a landscape on the threshold of change. Geomorphology 225, 25-35. doi: 10.1016/j.geomorph.2014.03.044

Fountain, A. G., Lyons, W. B., Burkins, M. B., Dana, G. L., Peter, T., Lewis, K. J., et al. (1999). Physical controls on the Taylor Valley ecosystem, Antarctica. Bioscience 49, 961-971. doi: 10.1525/bisi.1999.49.12.961

Fountain, A. G., Nylen, T. H., Monaghan, A., Basagic, H. J., and Bromwich, D. (2010). Snow in the McMurdo Dry Valleys, Antarctica. Intern. J. Climatol. 30, 633-642. doi: 10.1002/joc.1933

Friedmann, E. I. (1982). Endolithic microorganisms in the Antarctic cold desert. Science 215, 1045-1053. doi: 10.1126/science.215.4536.1045

Friedmann, E. I., and Ocampo, R. (1976). Endolithic blue-green algae in the Dry Valleys: primary producers in the Antarctic Desert ecosystem. Science 193, 1247-1249. doi: 10.1126/science.193.4259.1247

George, S., Fierer, N., Levy, J., and Adams, B. J. (2020). Operational taxonomic unit (OTU) table characterizing water track and adjacent soil microbial communities in Taylor Valley, Antarctica during the 2012-13 austral summer. Environ. Data Initiat. 1:74

Ghollarata, M., and Raiesi, F. (2007). The adverse effects of soil salinization on the growth of Trifolium alexandrinum $\mathrm{L}$. and associated microbial and biochemical properties in a soil from Iran. Soil Biol. Biochem. 39, 1699-1702. doi: 10.1016/j. soilbio.2007.01.024

Gooseff, M. N., Barrett, J. E., and Levy, J. S. (2013). Shallow groundwater systems in a polar desert, McMurdo Dry Valleys, Antarctica. Hydrogeol. J. 21, 171-183. doi: 10.1007/s10040-012-0926-923

Grenié, M., Denelle, P., Tucker, C. M., Munoz, F., and Violle, C. (2017). funrar: an R package to characterize functional rarity. Divers. Distribut. 23, 1365-1371. doi: 10.1111/ddi.12629

Gunde-Cimerman, N., Plemenitaš, A., and Oren, A. (2018). Strategies of adaptation of microorganisms of the three domains of life to high salt concentrations. FEMS Microbiol. Rev. 42, 353-375. doi: 10.1093/femsre/fuy009

Hallsworth, J. E., Yakimov, M. M., Golyshin, P. N., Gillion, J. L. M., D’Auria, G., De Lima Alves, F., et al. (2007). Limits of life in $\mathrm{MgCl} 2$-containing environments: chaotropicity defines the window. Environ. Microbiol. 9, 801-813. doi: 10.1111/ j.1462-2920.2006.01212.x

Harris, K. J., Carey, A. E., Lyons, W. B., Welch, K. A., and Fountain, A. G. (2007). Solute and isotope geochemistry of subsurface ice melt seeps in Taylor Valley, Antarctica. Bull. Geol. Soc. Am. 119, 548-555. doi: 10.1130/B25913.1

Hawes, I., and Howard-Williams, C. (2013). "Primary production processes in streams of the McMurdo Dry Valleys, Antarctica," in Ecosystem Dynamics in a Polar Desert: The Mcmurdo Dry Valleys, Antarctica, ed. J. C. Priscu (Washington, DC: American Geophysical Union), 129-140. doi: 10.1029/ ar072p0129

IBM (2016). IBM SPSS Statistics for Windows. Armonk, NY: IBM Corp.

Kimbrel, J. A., Ballor, N., Wu, Y. W., David, M. M., Hazen, T. C., Simmons, B. A., et al. (2018). Microbial community structure and functional potential along a hypersaline gradient. Front. Microbiol. 9:1492. doi: 10.3389/fmicb.2018.01492

Lahti, L., and Shetty, S. (2012). microbiome R Package.

Langford, Z. L., Gooseff, M. N., and Lampkin, D. J. (2015). Spatiotemporal dynamics of wetted soils across a polar desert landscape. Antarct. Sci. 27, 197-209. doi: 10.1017/S0954102014000601

Lauber, C. L., Hamady, M., Knight, R., and Fierer, N. (2009). Pyrosequencing-based assessment of soil $\mathrm{pH}$ as a predictor of soil bacterial community structure at the continental scale. Appl. Environ. Microbiol. 75, 5111-5120. doi: 10.1128/AEM. 00335-339
Lee, C. K., Barbier, B. A., Bottos, E. M., McDonald, I. R., and Cary, S. C. (2012). The inter-valley soil comparative survey: the ecology of dry valley edaphic microbial communities. ISME J. 6, 1046-1057. doi: 10.1038/ismej.2011.170

Lee, K. C., Caruso, T., Archer, S. D. J., Gillman, L. N., Lau, M. C. Y., Craig Cary, S., et al. (2018). Stochastic and deterministic effects of a moisture gradient on soil microbial communities in the McMurdo dry valleys of Antarctica. Front. Microbiol. 9:2619. doi: 10.3389/fmicb.2018.02619

Levy, J. (2012). Hydrological characteristics of recurrent slope lineae on Mars: evidence for liquid flow through regolith and comparisons with Antarctic terrestrial analogs. Icarus 219, 1-4. doi: 10.1016/j.icarus.2012.02.016

Levy, J. (2015). A hydrological continuum in permafrost environments: the morphological signatures of melt-driven hydrology on Earth and Mars. Geomorphology 240, 70-82. doi: 10.1016/j.geomorph.2014.02.033

Levy, J. S., Fountain, A. G., Gooseff, M. N., Barrett, J. E., Vantreese, R., Welch, K. A., et al. (2013). Water track modification of soil ecosystems in the Lake Hoare basin, Taylor Valley, Antarctica. Antarct. Sci. 26, 153-162. doi: 10.1017/ S095410201300045X

Levy, J. S., Fountain, A. G., Gooseff, M. N., Welch, K. A., and Lyons, W. B. (2011). Water tracks and permafrost in Taylor Valley, Antarctica: extensive and shallow groundwater connectivity in a cold desert ecosystem. Bull. Geol. Soc. Am. 123, 2295-2311. doi: 10.1130/B30436.1

Levy, J. S., Fountain, A. G., Welch, K. A., and Lyons, W. B. (2012). Hypersaline "wet patches" in Taylor Valley, Antarctica. Geophys. Res. Lett. 39, 1-5. doi: 10.1029/2012GL050898

Lozupone, C. A., and Knight, R. (2007). Global patterns in bacterial diversity. Proc. Natl. Acad. Sci. U.S.A. 104, 11436-11440. doi: 10.1073/pnas.0611525104

Mahaffy, P. R., Webster, C. R., Atreya, S. K., Franz, H., Wong, M., Conrad, P. G., et al. (2013). Abundance and isotopic composition of gases in the martian atmosphere from the Curiosity rover. Science 341, 263-266. doi: 10.1126/ science. 1237966

Martín-Torres, F. J., Zorzano, M.-P., Valentín-Serrano, P., Harri, A.-M., Genzer, M., Kemppinen, O., et al. (2015). Transient liquid water and water activity at Gale crater on Mars. Nat. Geosci. 8, 357-361. doi: 10.1038/ngeo2412

McDonald, D., Price, M. N., Goodrich, J., Nawrocki, E. P., Desantis, T. Z., Probst, A., et al. (2012). An improved Greengenes taxonomy with explicit ranks for ecological and evolutionary analyses of bacteria and archaea. ISME J. 6, 610-618. doi: 10.1038/ismej.2011.139

McEwen, A. S., Ojha, L., Dundas, C. M., Mattson, S. S., Byrne, S., Wray, J. J., et al. (2011). Seasonal flows on warm Martian slopes. Science 333, 740-743. doi: $10.1126 /$ science. 1204816

McKnight, D. M., Tate, C. M., Andrews, E. D., Niyogi, D. K., Cozzetto, K., Welch, K., et al. (2007). Reactivation of a cryptobiotic stream ecosystem in the McMurdo Dry Valleys, Antarctica: a long-term geomorphological experiment. Geomorphology 89, 186-204. doi: 10.1016/j.geomorph.2006.07.025

Mevs, U., Stackebrandt, E., Schumann, P., Gallikowski, C. A., and Hirsch, P. (2000). Modestobacter multiseptatus gen. nov., sp. nov., a budding actinomycete from soils of the Asgard Range (Transantarctic Mountains). Intern. J. Syst. Evol. Microbiol. 50, 337-346. doi: 10.1099/00207713-50-1-337

Niederberger, T. D., Sohm, J. A., Gunderson, T. E., Parker, A. E., Tirindelli, J., Capone, D. G., et al. (2015). Microbial community composition of transiently wetted Antarctic Dry Valley soils. Front. Microbiol. 6:9. doi: 10.3389/fmicb.2015. 00009

Nylen, T. H., Fountain, A. G., and Doran, P. T. (2004). Climatology of katabatic winds in the McMurdo Dry Valleys, southern Victoria Land, Antarctica. J. Geophys. Res. D Atmos. 109, 1-9. doi: 10.1029/2003jd003937

O'Brien, F. J. M., Almaraz, M., Foster, M. A., Hill, A. F., Huber, D. P., King, E. K., et al. (2019). Soil salinity and $\mathrm{pH}$ drive soil bacterial community composition and diversity along a lateritic slope in the Avon river critical zone observatory, Western Australia. Front. Microbiol. 10:1486. doi: 10.3389/fmicb.2019.01486

Ojha, L., Wilhelm, M. B., Murchie, S. L., McEwen, A. S., Wray, J. J., Hanley, J., et al. (2015). Spectral evidence for hydrated salts in recurring slope lineae on Mars. Nat. Geosci. 8, 829-832. doi: 10.1038/ngeo2546

Oksanen, J., Blanchet, F. G., Friendly, M., Kindt, R., Legendre, P., McGlinn, D., et al. (2019). vegan: Community Ecology Package.

Oren, A. (2013). "Life in magnesium- and calcium-rich hypersaline environments: Salt stress by chaotropic ions," in Polyextremophiles. Cellular Origin, Life in Extreme Habitats and Astrobiology, eds J. Seckbach, A. Oren, and H. Stan-Lotter (Dordrecht: Springer), 215-232. doi: 10.1007/978-94-007-6488-0_8 
Peeters, K., Hodgson, D. A., Convey, P., and Willems, A. (2011). Culturable diversity of heterotrophic bacteria in Forlidas Pond (Pensacola Mountains) and Lundström Lake (Shackleton Range), Antarctica. Microb. Ecol. 62, 399-413. doi: 10.1007/s00248-011-9842-7

Pointing, S. B., Chan, Y., Lacap, D. C., and Lau, M. C. Y. (2009). Highly specialized microbial diversity in hyper-arid polar desert. Proc. Natl. Acad. Sci. U.S.A. 106, 19964-19969. doi: 10.1073/pnas.0908274106

Prober, S. M., Leff, J. W., Bates, S. T., Borer, E. T., Firn, J., Harpole, W. S., et al. (2015). Plant diversity predicts beta but not alpha diversity of soil microbes across grasslands worldwide. Ecol. Lett. 18, 85-95. doi: 10.1111/ele.12381

R Core Team (2017). R: A Language and Environment for Statistical Computing. Vienna: R Foundation for Statistical Computing.

Rainey, F. A., Ray, K., Ferreira, M., Gatz, B. Z., Nobre, M. F., Bagaley, D., et al. (2005). Extensive diversity of ionizing-radiation-resistant bacteria recovered from Sonoran Desert soil and description of nine new species of the genus Deinococcus obtained from a single soil sample. Appl. Environ. Microbiol. 71, 5225-5235. doi: 10.1128/AEM.71.9.5225-5235.2005

Rath, K. M., Fierer, N., Murphy, D. V., and Rousk, J. (2019). Linking bacterial community composition to soil salinity along environmental gradients. ISME J. 13, 836-846. doi: 10.1038/s41396-018-0313-318

Rath, K. M., and Rousk, J. (2015). Salt effects on the soil microbial decomposer community and their role in organic carbon cycling: a review. Soil Biol. Biochem. 81, 108-123. doi: 10.1016/j.soilbio.2014.11.001

Rennó, N. O., Bos, B. J., Catling, D., Clark, B. C., Drube, L., Fisher, D., et al. (2009). Possible physical and thermodynamical evidence for liquid water at the Phoenix landing site. J. Geophys. Res. 114:E00E03326. doi: 10.1029/2009JE003362

Rietz, D. N., and Haynes, R. J. (2003). Effects of irrigation-induced salinity and sodicity on soil microbial activity. Soil Biol. Biochem. 35, 845-854. doi: 10.1016/ S0038-0717(03)00125-121

Rummel, J. D., Beaty, D. W., Jones, M. A., Bakermans, C., Barlow, N. G., Boston, P. J., et al. (2014). A new analysis of Mars "Special Regions": findings of the second MEPAG special regions science analysis group (SR-SAG2). Astrobiology 14, 887-968. doi: 10.1089/ast.2014.1227

Sardinha, M., Müller, T., Schmeisky, H., and Joergensen, R. G. (2003). Microbial performance in soils along a salinity gradient under acidic conditions. Appl. Soil Ecol. 23, 237-244. doi: 10.1016/S0929-1393(03)00027-21

Schmidt, F., Andrieu, F., Costard, F., Kocifaj, M., and Meresescu, A. G. (2017). Formation of recurring slope lineae on Mars by rarefied gas-triggered granular flows. Nat. Geosci. 10, 270-273. doi: 10.1038/ngeo2917

Seinfeld, J. H., and Pandis, S. N. (2006). Atmospheric Chemistry and Physics: From Air Pollution to Climate Change. New Jersey: John Wiley \& Sons, Ltd.

Sirisena, K. A., Ramirez, S., Steele, A., and Glamoclija, M. (2018). Microbial diversity of hypersaline sediments from Lake Lucero playa in White sands national monument, New Mexico, USA. Microb. Ecol. 76, 404-418. doi: 10. 1007/s00248-018-1142-z

Smith, J. L., Barrett, J. E., Tusnády, G., Rejtö, L., and Cary, S. C. (2010). Resolving environmental drivers of microbial community structure in Antarctic soils. Antarct. Sci. 22, 673-680. doi: 10.1017/S0954102010000763

Smith, P. H., Tamppari, L. K., Arvidson, R. E., Bass, D., Blaney, D., Boynton, W. V., et al. (2009). $\mathrm{H}_{2} \mathrm{O}$ at the phoenix landing site. Science 325, 58-61. doi: 10.1126/science.1172339

Stanish, L. F., O’Neill, S. P., Gonzalez, A., Legg, T. M., Knelman, J., McKnight, D. M., et al. (2013). Bacteria and diatom co-occurrence patterns in microbial mats from polar desert streams. Environ. Microbiol. 15, 1115-1131. doi: 10. $1111 / \mathrm{j} .1462-2920.2012 .02872 . \mathrm{x}$

Stillman, D. E., Michaels, T. I., and Grimm, R. E. (2017). Characteristics of the numerous and widespread recurring slope lineae (RSL) in Valles Marineris, Mars. Icarus 285, 195-210. doi: 10.1016/j.icarus.2016.10.025

Thompson, L. R., Sanders, J. G., McDonald, D., Amir, A., Ladau, J., Locey, K. J., et al. (2017). A communal catalogue reveals Earth's multiscale microbial diversity. Nature 551, 457-463. doi: 10.1038/nature24621

Toner, J. D., Sletten, R. S., and Prentice, M. L. (2013). Soluble salt accumulations in Taylor Valley, Antarctica: implications for paleolakes and Ross Sea Ice Sheet dynamics. J. Geophys. Res. 118, 198-215. doi: 10.1029/2012JF002467

Van Horn, D. J., Okie, J. G., Buelow, H. N., Gooseff, M. N., Barrett, J. E., and Takacs-Vesbach, C. D. (2014). Soil microbial responses to increased moisture and organic resources along a salinity gradient in a polar desert. Appl. Environ. Microbiol. 80, 3034-3043. doi: 10.1128/AEM.03414-3413

Van Horn, D. J., Van Horn, M. L., Barrett, J. E., Gooseff, M. N., Altrichter, A. E., Geyer, K. M., et al. (2013). Factors controlling soil microbial biomass and bacterial diversity and community composition in a cold desert ecosystem: role of geographic scale. PLoS One 8:e66103. doi: 10.1371/journal.pone.006 6103

Van Trappen, S., Vandecandelaere, I., Mergaert, J., and Swings, J. (2004). Gillisia limnaea gen. nov., sp. nov., a new member of the family Flavobacteriaceae isolated from a microbial mat in Lake Fryxell, Antartica. Intern. J. Syst. Evol. Microbiol. 54, 445-448. doi: 10.1099/ijs.0.02922-2920

Vincent, W. F., Downes, M. T., Castenholz, R. W., and Howard-Williams, C. (1993). Community structure and pigment organisation of cyanobacteriadominated microbial mats in antarctica. Eur. J. Phycol. 28, 213-221. doi: 10. 1080/09670269300650321

Wang, Q., Garrity, G. M., Tiedje, J. M., and Cole, J. R. (2007). Naïve Bayesian classifier for rapid assignment of rRNA sequences into the new bacterial taxonomy. Appl. Environ. Microbiol. 73, 5261-5267. doi: 10.1128/AEM.00 062-67

Wordsworth, R. D. (2016). "The climate of early Mars," in Annual Review of Earth and Planetary Sciences, Vol. 44, eds R. Jeanloz and K. H. Freeman (Palo Alto: Annual Reviews), 381-408.

Yuan, B. C., Li, Z. Z., Liu, H., Gao, M., and Zhang, Y. Y. (2007). Microbial biomass and activity in salt affected soils under arid conditions. Appl. Soil Ecol. 35, 319-328. doi: 10.1016/j.apsoil.2006.07.004

Zeglin, L. H., Dahm, C. N., Barrett, J. E., Gooseff, M. N., Fitpatrick, S. K., and Takacs-Vesbach, C. D. (2011). Bacterial community structure along moisture gradients in the parafluvial sediments of two ephemeral desert streams. Microb. Ecol. 61, 543-556. doi: 10.1007/s00248-010-9782-9787

Conflict of Interest: The authors declare that the research was conducted in the absence of any commercial or financial relationships that could be construed as a potential conflict of interest.

Copyright (c) 2021 George, Fierer, Levy and Adams. This is an open-access article distributed under the terms of the Creative Commons Attribution License (CC BY). The use, distribution or reproduction in other forums is permitted, provided the original author(s) and the copyright owner(s) are credited and that the original publication in this journal is cited, in accordance with accepted academic practice. No use, distribution or reproduction is permitted which does not comply with these terms. 